Research report

\title{
Parental and child fruit consumption in the context of general parenting, parental education and ethnic background is
}

\author{
Gerda Rodenburg ${ }^{\mathrm{a}, \mathrm{b}, *}$, Anke Oenema ${ }^{\mathrm{c}}$, Stef P.J. Kremers ${ }^{\mathrm{c}}$, Dike van de Mheen ${ }^{\mathrm{a}, \mathrm{b}}$ \\ a IVO Addiction Research Institute, Heemraadssingel 194, 3021 DM Rotterdam, The Netherlands \\ ${ }^{\mathrm{b}}$ Erasmus Medical Center, P.O. Box 2040, 3000 CA Rotterdam, The Netherlands \\ ${ }^{\mathrm{c}}$ Department of Health Promotion, Maastricht University, P.O. Box 616, 6200 MD Maastricht, The Netherlands
}

\section{A R T I C L E I N F O}

\section{Article history:}

Received 16 July 2011

Received in revised form 26 October 2011

Accepted 1 November 2011

Available online 7 November 2011

\section{Keywords:}

Child fruit consumption

Parental fruit consumption

General parenting

Parenting style

Psychological control

Behavioural control

Involvement

Parental education

Ethnicity

Role modelling

\begin{abstract}
A B S T R A C T
This study examines the association between parental and child fruit consumption in the context of general parenting, parental education and ethnic background. A cross-sectional study was performed among 1762 parent-child dyads. Mean age of the children was 8 years. One parent completed a questionnaire to measure their own and their child's fruit consumption, parenting style, education level and ethnicity. In mediation and moderation analyses, child fruit consumption was regressed on parental fruit consumption, parenting style, parental education and ethnicity. Participating children consumed on average 7.5 pieces of fruit per week. Fourteen percent met the recommended Dutch norm of two pieces of fruit per day. Parental and child fruit consumption were positively associated. The association was more pronounced under higher levels of psychological control and behavioural control, and among ethnic groups. Additionally, parental education and child fruit consumption were positively associated. Parental fruit consumption partially mediated this association. Interventions are needed to increase child fruit consumption. Interventions should focus on increasing parental fruit consumption and positive parental modelling, with particular focus on low-SES families. Additionally, interventions that combine positive modelling with positive general parenting skills (e.g. increasing behavioural control) may be more effective than interventions that focus on parental modelling alone.
\end{abstract}

(c) 2011 Elsevier Ltd. All rights reserved.

\section{Introduction}

Diets rich in fruit are associated with important health protective effects, including a healthy body weight (Alinia, Hels, \& Tetens, 2009; Lock, Pomerleau, Causer, Altmann, \& McKee, 2005; World Health Organization, 2002, 2003). It is widely acknowledged that children consume less fruit than is recommended (Currie et al., 2004; Guenther, Dodd, Reedy, \& Krebssmith, 2006; Huybrechts et al., 2008; Jones, Steer, Rogers, \& Emmett, 2010), and that dietary habits established in childhood track through to adulthood (Kelder, Perry, Klepp, \& Lytle, 1994; Mikkilä, Räsänen, Raitakari, Pietinen, \& Viikari, 2004). Because it is important to increase fruit consumption at an early age, detailed understanding of the determinants of children's fruit consumption is needed.

\footnotetext{
Acknowledgements: The authors declare that there are no conflicts of interest. The authors alone are responsible for the content and writing of the paper. Financial support for our study was provided by ZonMw, the Netherlands Organisation for Health Research and Development (Grant ID No. 121010011). All research by G. Rodenburg is financed by IVO Addiction Research Institute Rotterdam and by the Department of Public Health, Erasmus Medical Center Rotterdam. None of the funding sources had any influence on the data analyses, interpretation and presentation.

* Corresponding author.

E-mail address: rodenburg@ivo.nl (G. Rodenburg).
}

The home environment is a critical context for the development of eating behaviours (Tinsley, 2003). Parents are primarily responsible for shaping the home environment, e.g. by creating availability of and accessibility to foods, by expressing norms and values, by setting rules and regulations, and with their own behaviour. Therefore, examining parental factors and their potential relationship with children's fruit intake is important to understand child fruit consumption (Pearson, Biddle, \& Gorely, 2008; Ventura \& Birch, 2008; Vereecken, Rovner, \& Maes, 2010). Review studies on (parental) correlates of child fruit consumption showed a consistent and positive association between parental fruit intake and child fruit intake (Pearson et al., 2008; Rasmussen et al., 2006; Van Der Horst et al., 2007a), which is often interpreted as observational learning or modelling (Social Learning Theory, (Bandura, 1977)).

The association between parental fruit intake and child fruit intake has generally been studied in an isolated perspective by examining the primary (direct) relation. There is no insight into the potential underlying mechanisms of the association between parental and child fruit intake with higher-level contextual correlates, such as parenting style, parental education and ethnic background.

Therefore, this study explores the relationship between parental and child fruit intake in the context of these higher-level parental 


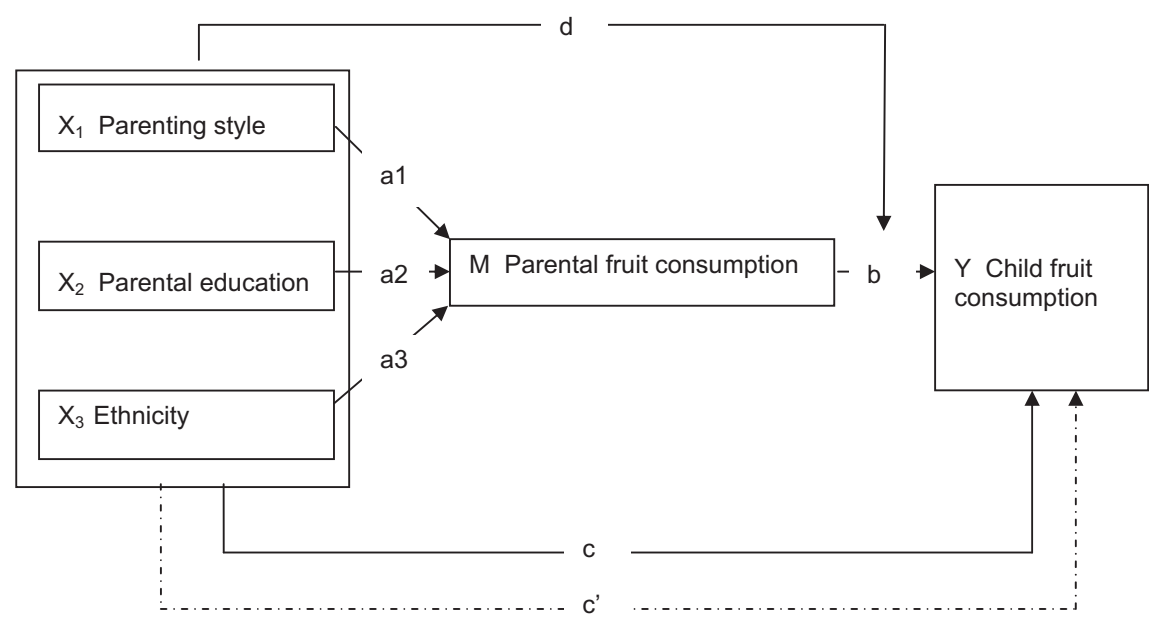

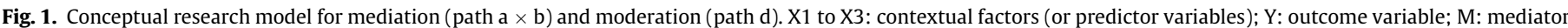

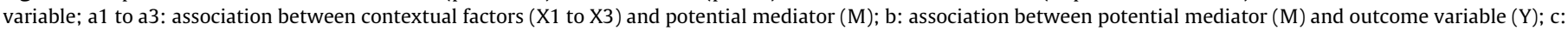

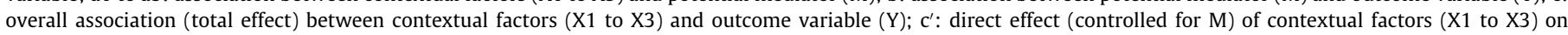
outcome variable $(\mathrm{Y})$; d: interaction between contextual factors (X1 to X3) and potential mediator (M) in predicting outcome variable (Y).

factors. We constructed a research model in which parental and child fruit intake as well as parenting style, parental education and ethnic background were incorporated (Fig. 1). According to social-cognitive theories such as the Theory of Triadic Influence (Flay, Snyder, \& Petraitis, 2009), parenting style, parental education and ethnic background were conceptualised as distal parental factors. These factors could be mediated by parental fruit consumption in explaining child fruit consumption, assuming that the distal parental factors 'cause' parental fruit consumption, which in turn 'causes' child fruit consumption (path $a \times$ path $b$, Fig. 1 ). In addition, in line with the ecological systems theory (Bronfenbrenner, 1979) and suggestions from others (e.g. Joyce \& Zimmer-Gembeck, 2009; Kremers, 2010; Kremers, Brug, De Vries, \& Engels, 2003; Rhee, 2008; Ventura \& Birch, 2008), we conceptualised parenting style, parental education and ethnic background as potential higher-order moderators, implying that the impact of parental modelling (i.e. parental fruit intake) on child fruit intake can vary depending on these higher-level conditions (path d, Fig. 1).

Parenting style or general parenting can be defined as 'a constellation of attitudes toward the child that are communicated to the child and that, taken together, create an emotional climate in which the parent's behaviours are expressed' (Darling \& Steinberg, 1993). In research it is usually operationalized in two dimensions (support and behavioural control) (Darling \& Steinberg, 1993; Steinberg, Elmen, \& Mounts, 1989), but the concept originally consists of three underlying dimensions: support, behavioural control and psychological control. Support (or involvement) refers to parental responsiveness and connectedness to the child. Behavioural (or strict) control refers to the regulation of the child's behaviour through firm and consistent discipline. Psychological control refers to the regulation of the child's behaviour through psychological means such as love withdrawal and guilt induction, e.g. behaving in a cool and unfriendly way when a child misbehaves or making a child feel guilty when it gets low grades in school. Psychological control is a more manipulative, suppressive form of control (Baumrind, 1966, 1971; Den Exter Blokland, Engels, \& Finkenauer, 2001; Maccoby \& Martin, 1983; Schachter, Goldman, \& Gordon, 1968; Steinberg et al., 1989) and is seen as a risk factor for problem behaviour (Barber \& Harmon, 2002; Finkenauer, Engels, \& Baumeister, 2005; Rodenburg, Kremers, Oenema, \& Van de Mheen, 2011). Researchers have increasingly called for the dimension of psychological control to be included in parenting research (Barber,
1996; Barber \& Harmon, 2002; Gray \& Steinberg, 1999; Rodenburg et al., 2011; Snoek, Engels, Janssens, \& van Strien, 2007; Steinberg, Lamborn, Darling, Mounts, \& Dornbusch, 1994), e.g. to clarify inconsistent findings relating parenting to dietary behaviours (Snoek et al., 2007). Therefore, we included psychological control and operationalized parenting style in three dimensions: support, behavioural control and psychological control.

The main aim of this study was to explore whether contextual factors influence the relationship between parental and child fruit consumption, to ultimately make recommendations for better-targeted prevention interventions. We examined two potential pathways through which contextual factors could influence this relationship, by examining contextual factors as distal parental factors and as potential moderators of the relationship between parental and child fruit consumption. Based on our research model, we formulated the following research questions: (1) are parental and child fruit consumption correlated? (2) are parenting style, parental education and ethnic background mediated determinants for parental fruit consumption in relation to child fruit consumption? and (3) are parenting style, parental education and ethnic background moderators of the relationship between parental fruit consumption and child fruit consumption?

\section{Methods}

\section{Study design and procedure}

A cross-sectional study was conducted as part of the INPACT study, which consists of 1840 parent-child dyads. INPACT (IVO Nutrition and Physical Activity Child cohorT) is an observational study (initiated in 2008) focusing on modifiable determinants of overweight in the home environment of children in the Netherlands (aged 8-12 years), with a specific emphasis on parental influences.

After approval for the INPACT study was obtained from the Ethical Committee of the Erasmus Medical Center Rotterdam, the first wave of data collection took place in the autumn of 2008 at Dutch primary schools in southern Netherlands (Eindhoven area). In recruiting the schools we collaborated with the Municipal Health Authority for Eindhoven and surrounding area (GGD BrabantZuidoost). The Municipal Health Authority invited all general primary schools in their service area to participate in the INPACT 
study. Of the 265 schools invited, 91 took part. The response rate from rural and urban schools was equal. The primary caregivers of third- grade students (aged about 8 years) were invited to participate in the cohort study, together with their child. Of the 2948 parent-child dyads invited, 1840 (62.4\%) gave informed consent to participate in the INPACT study for four years.

The present study was based on the first wave of data collection. The primary caregiver filled in a questionnaire at home, recording data on dietary behaviours of the child, and potentially relevant home environmental factors, including the primary caregiver's dietary behaviours, the three parenting dimensions, and socio-demographic variables. Of the 1840 participating parent-child dyads, 1762 were included in the present study (96\%). We excluded parent-child dyads with no or invalid data on demographics (child age, child gender, child ethnicity and primary caregiver's education level), parental fruit consumption and/or child fruit consumption.

\section{Sample characteristics}

The age of most participating children was $8(77 \%)$ or $9(20 \%)$ years (range $7-10$ years, mean $=8.18$ years, $S D=0.46)$. Boys $(51 \%)$ and girls (49\%) were represented in almost equal numbers. Most of the primary caregivers who completed the questionnaire were female (92\%) and lived with a partner (92\%). Of the primary caregivers, $22 \%$ had finished education at a low level (primary school and lower vocational/lower general secondary education), $45 \%$ at medium level (intermediate vocational education, higher general secondary education and university preparatory) and 33\% at a high level (higher vocational education and university). Of all children, $16 \%$ were from a non-Dutch ethnic background with one or both parents born abroad: $9 \%$ from non-western countries $(n=156)$; $7 \%$ from western countries $(n=127)$. Participating children consumed on average 7.5 pieces of fruit per week $(S D=4.25)$ and their primary caregivers 7.4 $(\mathrm{SD}=5.25)$ pieces. A minority $(14 \%)$ of the participating children met the recommended Dutch norm of at least 14 pieces of fruit per week (Richtlijnen Voedselkeuze (Nutrition Guidelines), 2009), while 21\% of their parents did.

\section{Measures}

\section{Child fruit consumption (outcome variable)}

Child fruit consumption was measured with a questionnaire that was based on validated Food Frequency Questionnaires (Bogers, Van Assema, Kester, Westerterp, \& Dagnelie, 2004; Haraldsdottir et al., 2005). The primary caregivers reported how many days a week (a normal week) their children consumed fruit (fresh, bottled and/or canned; no juice), with answering categories ranging from 'none or less than 1 day a week' to '7 days a week'. Additionally, they reported the number of pieces of fruit consumed by their children on such a day. Answering categories were: ' 0 pieces per day', '0.5 piece per day', ' 1 piece per day', ' 1.5 pieces per day', ' 2 pieces per day', '2.5 pieces per day', ' 3 pieces per day' and 'more than 3 pieces per day'. Reported consumption of more than 3 pieces per day $(n=12)$ was recoded as 4 pieces. Total child fruit consumption was expressed in pieces per week and calculated by multiplying frequency and quantity. For descriptive purposes only, child fruit consumption was dichotomised into those who consumed less than 14 pieces per week and those who consumed 14 or more pieces per week, according to the recommended Dutch norms of two pieces of fruit per day (Richtlijnen Voedselkeuze (Nutrition Guidelines), 2009).

\section{Contextual factors: parenting style, parental education and ethnic background}

The parenting style of the primary caregiver was measured using the Dutch translation (Beyers \& Goossens, 1999) of an instrument based on earlier work by Steinberg et al. (Lamborn, Mounts, Steinberg, \& Dornbusch, 1991; Steinberg et al., 1989), which is used in many studies worldwide (Beyers \& Goossens, 1999; Huver, Engels, Vermulst, \& De Vries, 2007a; Kremers et al., 2003; Pearson, Atkin, Biddle, Gorely, \& Edwardson, 2010). This 22-item measure assessed three parenting-style dimensions (support, behavioural control and psychological control) using a response scale ranging from -2 (completely disagree) to +2 (completely agree). Support was measured with seven items, such as 'When my child gets a low grade in school, I offer to help him/ her' $(\alpha=0.71)$. These items were combined in one variable by summing the item scores [range -14 (low) to +14 (high)]. Behavioural control was also measured with seven items, such as 'I know exactly what my child does in his/her free time' and 'I try to know where my child goes after school' $(\alpha=0.72)$. As recommended by Stattin \& Kerr (2000), it measured both parental knowledge and behavioural monitoring. After summing the item scores, the behavioural control variable ranged from -14 (low) to +14 (high). Psychological control was measured with eight items, such as 'I make my child feel guilty when he/she gets a low grade in school' $(\alpha=0.72$ ). This variable ranged from -16 (low) to +16 (high).

Based on these three parenting-style dimensions, five parenting styles have been established: the authoritative (high support, high behavioural control, low psychological control), permissive (high support, low behavioural control, low psychological control), authoritarian (low support, high behavioural control, low psychological control), rejecting (low support, low behavioural control, high psychological control), and neglecting (low support, low behavioural control, low psychological control) parenting style (e.g. Goossens \& Beyers, 1999; Huver, Engels, Van Breukelen, \& De Vries, 2007b). For mediation analyses, we constructed these five parenting styles by dichotomising the sample on each dimension (median-split) and examining the three variables simultaneously. In moderation analyses we used the three separate, continuous parenting dimensions in order to make full use of our data (cf. Joyce \& Zimmer-Gembeck, 2009; Van der Horst et al., 2007b).

Parental education was measured by the education level of the primary caregiver and defined as low (primary school and lower vocational/lower general secondary education), medium (intermediate vocational education, higher general secondary education and university prep) or high (higher vocational education and university), according to international classification systems (Eurostat, 2007).

Ethnic background was defined by the parents' country of birth, according to standard procedures of Statistics Netherlands (2000). If both parents were born in the Netherlands the child was classified as native Dutch, if at least one parent was born outside the Netherlands but inside Europe (including former Yugoslavia and the Soviet Union, North America, Oceania, Indonesia or Japan), the child was classified as a western immigrant and if at least one parent was born in Turkey, Africa, Latin America or Asia the child was classified as a non-western immigrant. By differentiating between western and non-western immigrants we aimed to cover cultural differences that may importantly influence behaviour (Singh et al., 2009).

\section{Parental fruit consumption}

Primary caregiver's fruit consumption was measured, calculated and dichotomised in the same way as child fruit consumption.

\section{Potential confounders}

Child age and gender were assessed as potential confounders. Child age was measured in years by subtracting the date of questionnaire completion from child birth date. Ethnic background and parental education were included as control variables in models in which they were not a predictor variable. 


\section{Strategy for analyses}

To describe the study population and differences between subgroups, we computed means, standard deviations (SDs) and/or proportions for the socio-demographic variables and parenting styles. We also calculated median scores and interquartile ranges in pieces per week on child and parental fruit consumption for these variables. As fruit consumption variables showed a skewed distribution, differences between groups were analysed with a Mann-Whitney test (age, sex and parenting styles) or a Kruskal Wallis test (parental education and ethnic background).

Multivariate linear regression analyses were performed to establish (1) the relationship between parental fruit consumption and child fruit consumption, (2) primary associations between contextual factors and child fruit consumption (Fig. 1, path c), (3) mediated effects (Fig. 1, path $a \times$ path $b$ ), and (4) moderated effects (Fig. 1, path $\mathrm{d}$ ). In the regression analyses, child fruit consumption and parental fruit consumption were entered as continuous variables. Data were log-transformed by $\ln (\mathrm{x})$ due to the skewed distribution (Cooke et al., 2004; Tabachnick \& Fidell, 1996). To include children and primary caregivers who consumed zero pieces of fruit per week ( $n=39$ for children; $n=118$ for primary caregivers), a week consumption of 0 was recoded as 0.25 (Glass \& Gray, 2001). The unstandardized regression coefficients (Bs) obtained in the analyses using the log transformed variables were backtransformed $\left(e^{\mathrm{B}}\right)$ to present relative differences in fruit consumption in pieces per week.

The contextual factors were entered in the regression analyses as dummy variables. Five dummy variables were constructed to measure parenting style: authoritative parenting $(0=$ no; $1=$ yes), authoritarian parenting $(0=$ no; $1=$ yes $)$, permissive parenting $(0=$ no; $1=$ yes $)$, neglecting parenting $(0=$ no; $1=$ yes $)$ and rejecting parenting $(0=$ no; $1=$ yes). Two dummy variables were constructed to measure parental education, with a low education as reference group. The reference group for ethnic background was native Dutch.

\section{Primary associations}

Separate regression analyses were performed to establish primary relationships of parental fruit consumption, parenting style, parental education and ethnic background with child fruit consumption, adjusted for age, gender, parental education and/or ethnicity (see above: potential confounders).

\section{Mediation analyses}

Mediation analyses examined whether parental fruit consumption mediated the relationship between the contextual parental factors and child fruit consumption. According to MacKinnon, a mediator has to be associated with the predictor variable and with the outcome variable (MacKinnon, 2008). If these two conditions were met when tested in regression analyses, mediated effects and proportions mediated were calculated. The product-of coefficients method $(\mathrm{a} * \mathrm{~b})$ was used to calculate mediated effects, and the significance of mediation was tested with a Sobel-test (MacKinnon, 2008). Proportions mediated were calculated as the mediated effect divided by the total effect $([a * b] / c)$.

\section{Moderation analyses}

In the final set of regression analyses we examined whether parenting-style dimensions, parental education and ethnic background moderated the relationship between parental fruit consumption and child fruit consumption (Fig. 1, path d). Moderation was tested by adding interaction terms to the regression analyses with a significance level of 0.1 (Rosnow \& Rosenthal, 1989). If interaction terms were significant, stratified analyses were conducted. In order to make full use of our data, continuous parenting-style dimensions, instead of parenting styles, were used in parenting interaction terms (Joyce \& Zimmer-Gembeck, 2009; Van der Horst et al., 2007b).

All analyses were conducted using SPSS version 17.0.

\section{Results}

Descriptive statistics and median scores on child and parental fruit consumption

Table 1 summarises means, SDs and/or proportions for the socio-demographic variables and parenting styles, combined with calculated median scores and interquartile ranges in pieces per week on child fruit consumption and parental fruit consumption.

Median fruit consumption for children was 7.0 pieces per week (25th-75th percentile: 5.0-10.5) and for parents 6.0 pieces per week (25th-75th percentile: $5.0-10.5$ ). Analyses of median scores on child fruit consumption showed that rejecting parenting was the only parenting style that significantly differed in median child fruit consumption: children of rejecting parents consumed less fruit (median $=6.0 ; 25$ th-75th percentile: $4.0-9.0$ ) than children of non-rejecting parents (median $=7.0 ; 25$ th-75th percentile: 5.0-10.5)

For children as well as their parents, median fruit consumption was higher when they were higher educated. Western immigrant children consumed more fruit (median $=7.0$; 25th-75th percentile: $5.0-14.0$ ) than native Dutch children (median $=7.0 ; 25$ th75th percentile: 5.0-10.0), while parents of non-western immigrant children consumed more fruit (median $=7.0$; 25th75th percentile: $4.0-14.0$ ) than parents of native Dutch children (median $=6.0 ; 25$ th-75th percentile: $3.0-10.5$ ).

Children aged 7 and 8 years consumed significantly more fruit (median $=7.0 ; 25$ th-75th percentile: $5.0-10.5$ ) than children aged 9 and 10 years (median $=6.0 ; 25$ th -75 th: percentile $4.0-10.0$ ). Parents of children aged 7 and 8 years did not differ in fruit consumption from parents of children aged 9 and 10 years. There were no significant differences in child and parental fruit consumption between boys and girls.

\section{Primary associations}

Table 2 shows significant total (i.e. not adjusted for the mediator) and direct (i.e. adjusted for the mediator) effects of parental fruit consumption and the contextual factors on child fruit consumption. Adjusted for age, gender, parental education and ethnicity, parental fruit consumption and child fruit consumption were positively associated ( $B=0.22 ; p<0.001$; Table 2 , total effects). The relative difference (RD) was $1.17(p<0.001)$, if the parent would double his/her fruit intake.

Of the contextual parental factors, rejecting parenting, parental education and ethnicity (western immigrant versus native Dutch children) were significantly associated with child fruit consumption (Table 2, total effects). Children of rejecting parents consumed $12 \%$ less fruit than children of non-rejecting parents, children of highly educated parents consumed $23 \%$ more fruit than children of low educated parents, children of middle educated parents consumed $12 \%$ more fruit than children of low educated parents, and western immigrant children consumed $17 \%$ more fruit than native Dutch children.

\section{Mediation analyses: parental fruit consumption as a mediator}

As part of the mediation analyses, we tested whether contextual factors that were significantly associated with child fruit consumption were also associated with parental fruit consumption (path 
Table 1

General characteristics of the study population and median scores (pieces/week) on child and parental fruit consumption $(n=1762)$.

\begin{tabular}{|c|c|c|c|c|c|c|}
\hline & $n$ & $\begin{array}{l}\text { Proportion/ } \\
\text { mean (SD) }\end{array}$ & $\begin{array}{l}\text { Child fruit consumption: } \\
\text { median ( } 25 \text { th-75th } \\
\text { percentile) }\end{array}$ & $p$-value ${ }^{\mathrm{b}}$ & $\begin{array}{l}\text { Parental fruit consumption: } \\
\text { median }(25 \text { th-75th } \\
\text { percentile })^{\mathrm{a}}\end{array}$ & $p$-value ${ }^{b}$ \\
\hline Total sample & 1762 & & $7.0(5.0-10.5)$ & & $6.0(3.4-10.5)$ & \\
\hline $\begin{array}{l}\text { Authoritative parenting style } \\
\text { yes } \\
\text { no }\end{array}$ & $\begin{array}{r}341 \\
1421\end{array}$ & $\begin{array}{l}19.4 \% \\
80.6 \%\end{array}$ & $\begin{array}{l}7.0(5.0-10.5) \\
7.0(5.0-10.5)\end{array}$ & n.s. & $\begin{array}{l}7.0(3.0-13.3) \\
6.0(3.8-10.5)\end{array}$ & n.s. \\
\hline $\begin{array}{l}\text { Authoritarian parenting style } \\
\text { yes } \\
\text { no }\end{array}$ & $\begin{array}{r}155 \\
1607\end{array}$ & $\begin{array}{r}8.8 \% \\
91.2 \%\end{array}$ & $\begin{array}{l}7.0(5.0-10.5) \\
7.0(5.0-10.5)\end{array}$ & n.s. & $\begin{array}{l}7.0(4.0-12.0) \\
6.0(3.0-10.5)\end{array}$ & n.s. \\
\hline $\begin{array}{l}\text { Permissive parenting style } \\
\text { Yes } \\
\text { No }\end{array}$ & $\begin{array}{r}321 \\
1441\end{array}$ & $\begin{array}{l}18.2 \% \\
81.8 \%\end{array}$ & $\begin{array}{l}7.0(5.0-10.0) \\
7.0(5.0-10.5)\end{array}$ & n.s. & $\begin{array}{l}6.0(3.0-10.5) \\
6.0(3.5-10.5)\end{array}$ & n.s. \\
\hline $\begin{array}{l}\text { Neglecting parenting style } \\
\text { Yes } \\
\text { No }\end{array}$ & $\begin{array}{r}285 \\
1477\end{array}$ & $\begin{array}{l}16.2 \% \\
83.8 \%\end{array}$ & $\begin{array}{l}6.0(5.0-9.0) \\
7.0(5.0-10.5)\end{array}$ & n.s. & $\begin{array}{l}6.0(4.0-10.5) \\
6.0(3.0-10.5)\end{array}$ & n.s. \\
\hline $\begin{array}{l}\text { Rejecting parenting style } \\
\text { Yes } \\
\text { No }\end{array}$ & $\begin{array}{r}339 \\
1423\end{array}$ & $\begin{array}{l}19.2 \% \\
80.8 \%\end{array}$ & $\begin{array}{l}6.0(4.0-9.0) \\
7.0(5.0-10.5)\end{array}$ & 0.005 & $\begin{array}{l}6.0(3.0-10.5) \\
6.0(4.0-10.5)\end{array}$ & n.s. \\
\hline $\begin{array}{l}\text { Parental education } \\
\text { Low-level education } \\
\text { Medium-level education } \\
\text { High-level education }\end{array}$ & $\begin{array}{l}387 \\
800 \\
575\end{array}$ & $\begin{array}{l}22.0 \% \\
45.4 \% \\
32.6 \%\end{array}$ & $\begin{array}{l}6.0(4.0-10.0) \\
7.0(5.0-10.0) \\
7.0(5.0-10.5)\end{array}$ & $0.000^{c}$ & $\begin{array}{l}5.0(3.0-10.0) \\
6.0(3.0-10.5) \\
7.0(4.0-12.0)\end{array}$ & $0.000^{c}$ \\
\hline $\begin{array}{l}\text { Ethnic background } \\
\text { Native Dutch } \\
\text { Non-Western immigrant } \\
\text { Western immigrant }\end{array}$ & $\begin{array}{r}1479 \\
156 \\
127\end{array}$ & $\begin{array}{r}83.9 \% \\
8.9 \% \\
7.2 \%\end{array}$ & $\begin{array}{l}7.0(5.0-10.0) \\
7.0(4.0-10.5) \\
7.0(5.0-14.0)\end{array}$ & $0.005^{\mathrm{d}}$ & $\begin{array}{l}6.0(3.0-10.5) \\
7.0(4.0-14.0) \\
7.0(3.5-14.0)\end{array}$ & $0.025^{\mathrm{e}}$ \\
\hline $\begin{array}{l}\text { Child age (years) } \\
7 \text { \& } 8 \text { years } \\
9 \text { \& } 10 \text { years }\end{array}$ & $\begin{array}{r}1407 \\
355\end{array}$ & $8.18(0.49)$ & $\begin{array}{l}7.0(5.0-10.5) \\
6.0(4.0-10.0)\end{array}$ & 0.005 & $\begin{array}{l}6.0(4.0-10.5) \\
6.0(3.0-10.5)\end{array}$ & n.s. \\
\hline $\begin{array}{l}\text { Child gender } \\
\text { Boys } \\
\text { Girls }\end{array}$ & $\begin{array}{l}893 \\
869\end{array}$ & $\begin{array}{l}50.7 \% \\
49.3 \%\end{array}$ & $\begin{array}{l}7.0(5.0-10.5) \\
7.0(5.0-10.0)\end{array}$ & n.s. & $\begin{array}{l}7.0(4.0-10.5) \\
6.0(3.0-10.5)\end{array}$ & n.s \\
\hline
\end{tabular}

n.s. not significant.

a Ranges for child fruit consumption and parental fruit consumption: 0.25-28 pieces per week

b comparing groups, using the Mann-Whitney test (age, sex and parenting styles) or the Kruskal-Wallis test (ethnicity and parental education).

c Low < medium < high.

d Western immigrants and native Dutch different at $p=0.003$.

e Non-western immigrants and native Dutch different at $p=0.013$.

Table 2

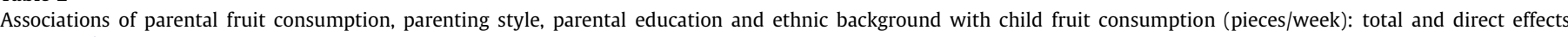
$(n=1762)^{\mathrm{a}}$.

\begin{tabular}{|c|c|c|c|c|c|c|c|c|c|c|}
\hline \multirow[b]{2}{*}{ Predictor } & \multicolumn{5}{|c|}{ Total effects $(\mathrm{c})^{\mathrm{b}}$} & \multicolumn{5}{|c|}{ Direct effects $\left(c^{\prime}\right)^{c}$} \\
\hline & $\overline{\mathrm{B}^{\mathrm{d}}}$ & $95 \% \mathrm{CI}$ & $R^{2 \mathrm{e}}$ & $\mathrm{RD}^{\mathrm{f}}$ & $95 \% \mathrm{CI}$ & B & $95 \% \mathrm{CI}$ & $R^{2}$ & $\mathrm{RD}$ & $95 \% \mathrm{CI}$ \\
\hline Parental fruit intake & $0.22^{* * * *}$ & $0.19 ; 0.26$ & 0.13 & $1.17^{* * *}, \mathrm{~g}$ & $1.14 ; 1.19$ & & & & & \\
\hline Rejecting parenting (yes/no) & $-0.12^{* *}$ & $-0.21 ;-0.04$ & 0.03 & $0.88^{* *}$ & $0.81 ; 0.97$ & NA & & & NA & \\
\hline Parental education (high/low) & $0.20^{* * *}$ & $0.11 ; 0.30$ & 0.03 & $1.23^{* * *}$ & $1.11 ; 1.35$ & $0.17^{*}$ & $0.02 ; 0.21$ & 0.13 & $1.12^{*}$ & $1.02 ; 1.23$ \\
\hline Parental education (middle/low) & $0.12^{*}$ & $0.03 ; 0.21$ & 0.03 & $1.12^{*}$ & $1.03 ; 1.23$ & 0.06 & $-0.02 ; 0.15$ & 0.13 & 1.07 & $0.98 ; 1.16$ \\
\hline Ethnicity (western immigrants/native Dutch) & $0.16^{*}$ & $0.02 ; 0.29$ & 0.03 & $1.17^{*}$ & $1.02 ; 1.34$ & NA & & & NA & \\
\hline
\end{tabular}

NA: not applicable, parental fruit consumption is not a significant mediator.

${ }^{*} p<0.05$.

*** $p<0.01$.

*** $p<0.001$.

a Table displays only significant total effects.

b Regression model adjusted for child gender, age, ethnic background and parental education.

c Regression model adjusted for child gender, age, ethnic background and parental education, additionally adjusted for significant mediator 'parental fruit consumption'.

d $B=$ unstandardised regression coefficient.

e $R^{2}=$ explained variance of model.

${ }^{\mathrm{f}} \mathrm{RD}=$ relative difference $=e^{\mathrm{B}}$. It indicates the relative change in child fruit consumption in pieces a week between comparison and reference group.

$\mathrm{g}$ As both parental fruit consumption and child fruit consumption were log transformed, the relative difference was calculated as $e^{\mathrm{B} \times \ln (2)}$, indicating the relative change in child fruit consumption in pieces a week for a doubling in parental fruit consumption.

a1-a3). For children of rejecting parents and western immigrant children, path a was non-significant (Table 3 ) and thus the criteria for mediation analysis were not met for these variables.
However, parental education (high vs. low and middle vs. low) was significantly associated with parental fruit consumption. Highly educated parents consumed $47 \%$ more fruit than low 
Table 3

Results from the mediation analyses with parental fruit consumption as mediator and child fruit consumption (pieces/week) as outcome variable $(n=1762){ }^{\mathrm{a}}$

\begin{tabular}{|c|c|c|c|c|c|c|}
\hline Predictor & B path $a^{b}$ & $95 \% \mathrm{CI}$ & RD path $a^{c}$ & $95 \% \mathrm{CI}$ & Mediated effect $a \times b^{d}$ & $\%$ mediated $(\mathrm{a} \times \mathrm{b} / \mathrm{c})^{\mathrm{e}}$ \\
\hline Rejecting parenting (yes/no) & -0.03 & $-0.15 ; 0.10$ & 0.97 & $0.86 ; 1.11$ & NA & NA \\
\hline Parental education (high/low) & $0.39^{* * *}$ & $0.25 ; 0.53$ & $1.47^{* * *}$ & $1.28 ; 1.69$ & $0.09^{* * *}$ & 42.8 \\
\hline Parental education (middle/low) & $0.24^{* * *}$ & $0.11 ; 0.36$ & $1.27^{* * *}$ & $1.11 ; 1.44$ & $0.05^{* * *}$ & 45.3 \\
\hline Ethnicity (western immigrants/native Dutch) & 0.06 & $-0.14 ; 0.25$ & 1.06 & $0.87 ; 1.28$ & NA & NA \\
\hline
\end{tabular}

NA: not applicable, parental fruit consumption is not a significant mediator.

${ }^{*} \mathrm{p}<0.05,{ }^{* *} \mathrm{p}<0.01,{ }^{* * *} \mathrm{p}<0.001$.

a Table displays only contextual factors that were significantly associated with child fruit consumption.

b Association between predictor and mediator (parental fruit consumption); $B=$ unstandardised regression coefficient.

c $\mathrm{RD}=$ relative difference $=e^{\mathrm{B}}$. It indicates the relative change in parental fruit consumption in pieces a week between comparison and reference group.

${ }^{d}$ Regression coefficient of path $b$ with parental education as predictor variable: 0.22 (CI: $\left.0.19,0.26 ; p<0.001\right)$.

e Percentage mediated calculated with the c-value for total effects, see Table 2

educated parents, and middle educated parents consumed $27 \%$ more fruit than low educated parents (Table 3). As parental fruit consumption was also significantly associated with child fruit consumption (path b), the criteria for mediation analysis were met. The last two columns of Table 3 show the estimated mediated effects and the proportion of the total effect that was mediated. The mediated effects for both parental education comparisons were significant. The proportion mediated was around $45 \%$, implying that parental fruit consumption explained about $45 \%$ of the association between parental education and child fruit consumption.

\section{Moderation analyses: contextual factors as moderators}

In the moderation analyses we tested whether the parenting dimensions support, behavioural control and psychological control, parental education and ethnic background modified the association between parental fruit consumption and child fruit consumption. Of the parenting dimensions, psychological control and behavioural control were found to moderate the parental fruit/child fruit association ( $p_{\text {interaction term }} 0.005$ and 0.077 , respectively). Stratified analyses (Table 4 ) revealed that the positive association was most pronounced in the highest quartile of psychological control $\left(R^{2}=19.8 \%\right.$ vs. $R^{2}=9.5 \%$ in lowest quartile) and in the two highest quartiles of behavioural control $\left(R^{2}=19.0 /\right.$ $18.2 \%$ vs. $R^{2}=11.2 / 11.1 \%$ in lowest quartiles). In addition, the relationship between parental and child fruit intake differed depend-

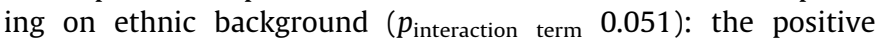
association was more pronounced in non-western and western immigrants than in native Dutch $\left(R^{2}\right.$ non-western immigrants $=19.2 \%$; $R^{2}$ western immigrants $=25.0 \%$ and $R^{2}$ native Dutch $\left.=10.8\right)$. Parental education and parental support did not moderate the association between parental and child fruit intake.

\section{Discussion}

This study, which analysed the association between parental and child fruit intake in the context of higher-level parental factors, shows that parental fruit consumption, parental education and a western immigrant background were positively associated with child fruit consumption. A new finding is that the relation between parental education and child fruit consumption was mediated by parental fruit consumption. We also demonstrated that the association between parental and child fruit consumption depends on higher-order moderators: the positive association was more

Table 4

Moderation analyses: association between parental and child fruit consumption, stratified by quartiles of psychological control, behavioural control and ethnicity ( $\mathrm{n}=1762$ )

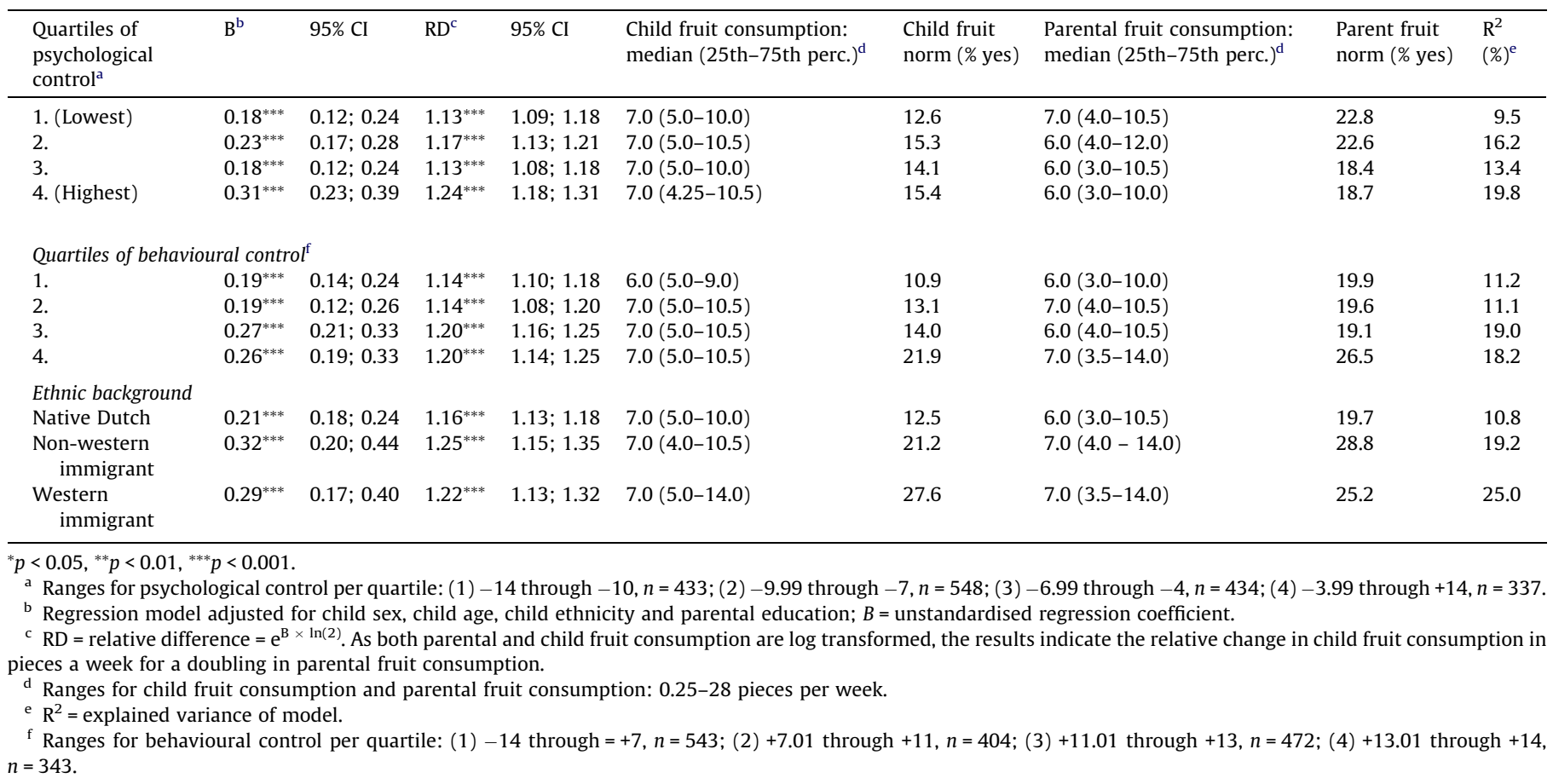


pronounced under higher levels of psychological control, higher levels of behavioural control, and in non-western and western immigrants. Finally, we found that rejecting parenting was negatively associated with child fruit intake, but not mediated by parental fruit intake.

In line with review studies and recent studies on parental correlates of child fruit intake (Pearson et al., 2008; Rasmussen et al., 2006; Van Der Horst et al., 2007a; Vereecken et al., 2010; Zeinstra, Koelen, Kok, Van der Laan, \& De Graaf, 2010), we found a positive association between parental and child fruit consumption. Moreover, because we found that only $14 \%$ of the children and $21 \%$ of the parents consumed in accordance with the recommended Dutch norm of at least 2 pieces of fruit per day (Richtlijnen Voedselkeuze (Nutrition Guidelines), 2009), improving parental fruit intake may be a useful approach for promoting fruit intake in children. Our results indicate that if parents would double their fruit consumption (which for most parents would mean complying with the guideline of two pieces of fruit per day), their child's fruit consumption would increase by $17 \%$. Although this potential increase in child fruit consumption may not seem large, a change in parental fruit consumption is feasible on a population basis (Pomerleau, Lock, Knai, \& McKee, 2005) and can contribute to increasing child fruit consumption to some extent. Interventions aimed at improving parental fruit consumption may become even more effective if parents are made aware of their role as a role model, and of how important a positive parental role model is for their child's health behaviour and health in general (Brown \& Ogden, 2004; Vereecken et al., 2010). To increase parental awareness, a mass-media campaign (commercials on television, posters on billboards, etc.) could be executed with an appealing slogan stating that children imitate. In more personal intervention sessions, parents could perform role model plays with good and bad behaviour to see how this influences their children's behaviour.

of the contextual factors studied, parental education, ethnicity, psychological control and behavioural control were related to parental and child fruit intake, either as mediated factor or as moderator. This demonstrates that contextual factors can influence the relationship between parental and child fruit consumption through a mediated pathway, as hypothesised in social cognitive models such as the Theory of Triadic Influence (i.e. distal parental factors 'causing' parental fruit consumption, which in turn 'causes' child fruit consumption), as well as through a moderated pathway, as derived from ecological systems theory (i.e. contextual factors as higher order moderators). A major challenge for future empirical studies regarding child dietary behaviour will be to document under what conditions higher order environmental moderation is most or least likely to occur (see also Kremers et al., 2006; Wachs, 1999).

The positive association between parental education and child fruit consumption, also found in a recent longitudinal study by Jones et al. (2010), was explained by parental fruit consumption for about $45 \%$. This finding may underline the previously stressed importance of targeting interventions at improving parental fruit intake, and that low educated parents need particular attention. Improving parental behaviour (i.e. increasing parental fruit intake) among low educated families may eventually contribute to diminishing socio-economic health inequalities.

Although a western immigrant background and rejecting parenting were associated with child fruit consumption, the associations were not mediated by parental fruit consumption. To improve our understanding of the relationship between parental and child fruit consumption, other potential parental higher-level conditions should also be included in future studies. Parental nutritional knowledge and availability/accessibility of fruit are related to fruit consumption (Blanchette \& Brug, 2005; Gibson, Wardle, \& Watts, 1998; Kratt, Reynolds, \& Shewchuk, 2000) and may be, together with parental feeding styles and healthy-eating policies, important contextual factors.

There is evidence that more global, higher-level factors such as parenting style and socio-demographic factors can provide a context for more specific parental behaviours in relation to child behaviour (Joyce \& Zimmer-Gembeck, 2009; Van der Horst et al., 2007b). In our study, the relationship between parental modelling (i.e. parental fruit intake) and child fruit intake differed depending on the levels of psychological control, behavioural control and ethnic background. Thus, our results are consistent with the evidence that higher-level parental factors can function as a contextual factor in which parental influences on child fruit intake occur, and need attention in future studies (Sleddens, Gerards, Thijs, De Vries, \& Kremers, 2011). Gaining more insight into the relationships within certain subgroups (such as SES groups and ethnic groups), can improve the focus of programs aimed at increasing child fruit consumption.

The moderating influence of psychological control demonstrated that the positive association between parental and child fruit intake was most pronounced among children who were subject to the highest levels of psychological control; these were children of rejecting parents. As rejecting parenting was negatively associated with child fruit consumption, the most pronounced association was among children with the lowest fruit consumption. An explanation for a more pronounced relation when children were subject to higher levels of psychological control could therefore be found in modelling. Because rejecting parents conduct low levels of involvement and behavioural control (including few explicit rules), the impact of modelling, in our case its negative impact, could be relatively large (Brown \& Ogden, 2004; Ogden, Reynolds, \& Smith, 2006). The influence of this negative role model of rejecting parents is not supportive for healthful child behaviour; this may justify aims to prevent this parenting style, which is seen as a risk factor for problem behaviour in general (Barber \& Harmon, 2002; Finkenauer et al., 2005; Rodenburg et al., 2011).

The positive relationship between parental and child fruit consumption was more pronounced among children who were subject to the highest levels of behavioural control. Especially in the highest quartile, the percentage of parents complying with the norm of two pieces of fruit per day was relatively large (26.5\% vs. 19.1 $19.9 \%$ ), indicating that these parents have a relatively high fruit consumption and could thus function as positive role models. This makes focusing on increasing behavioural control in combination with increasing parental fruit consumption a potentially interesting aspect of intervention programs (Gerards, Sleddens, Dagnelie, De Vries, \& Kremers, 2011).

The moderating influence of ethnicity showed a more pronounced association between parental and child fruit intake among western and non-western immigrant children compared to native Dutch. Furthermore, we found a higher fruit consumption in western (17\% higher consumption, significant) and non-western immigrant children (11\% higher consumption; non-significant) than among native Dutch children. Together with the finding that the percentage of parents complying with the norm of two pieces of fruit per day was relatively large among migrant groups $(28.8 \%$ for non-western and $25.2 \%$ for western immigrants) compared to native Dutch (19.7\%), this indicates that immigrant parents are a better fruit consumption role model for their children than native Dutch parents. The reason for the higher fruit consumption in migrant groups may be related to cultural differences (Singh et al., 2009). For example, in southern-European countries fruit is abundant and easily available/accessible, resulting in a habit of fruit eating (they indeed have the highest fruit consumption of Europe (Agudo et al., 2002)), which is carried into the host country when migrating. 


\section{Strengths and limitations}

An important aspect of our study is that we moved beyond the isolated perspective of looking at primary associations of environmental factors with behaviour, and created a model of parent-level influences in which moderation and mediation processes were integrated to better understand the mechanism underlying child fruit consumption. In addition, as far as we know, no other studies on child fruit consumption have measured parenting style threedimensionally (Sleddens et al., 2011).

A limitation of our study is that we analysed cross-sectional data. The relationship between parental fruit consumption and child fruit consumption might be bi-directional. Current literature offers few insights into the bidirectional processes through which parents and children constantly shape and reshape each other through their mutual actions and reactions (Kerr \& Stattin, 2000; O'Connor, 2002). To further elucidate cause and effect, longitudinal analyses are needed. In addition, we used a food frequency questionnaire to measure fruit consumption, which may evoke social desirability bias and lead to overestimation of fruit consumption (Baranowski, 1997; Van Assema, Brug, Ronda, Steenhuis, \& Oenema, 2002) in parents and children. This implies that actual fruit consumption and the percentage of children and parents meeting fruit recommendations could be lower, thus further emphasising the need for interventions to increase fruit consumption in children and parents.

\section{Conclusion}

Parental and child fruit consumption were positively associated. The association was more pronounced under higher levels of psychological control, higher levels of behavioural control and among ethnic groups. In addition, parental education and child fruit consumption were positively associated. Parental fruit consumption partially mediated the association between parental education and child fruit consumption (45\% explained). These findings provide updated input for future interventions. Interventions are needed as only $14 \%$ of the children in our study met the recommended Dutch norms for fruit intake. Interventions should focus on increasing parental fruit consumption, and make parents aware of their role as a role model. Parents who consume sufficient amounts of fruit are a positive role model for their children, and this positive modelling should be encouraged.

In interventions, special attention should be given to increasing parental and child fruit consumption in families with low educated parents. In addition, interventions that combine positive modelling with positive general parenting skills (e.g. diminishing psychological control and increasing behavioural control) may have a stronger effect than interventions that focus only on food-related parenting practices.

\section{References}

Agudo, A., Slimani, N., Ocké, M., Naska, A., Miller, A., Kroke, A., \& Bamia, C. (2002) Consumption of vegetables, fruit and other plant foods in the European prospective investigation into cancer and nutrition (epic) cohorts from 10 European countries. Public Health Nutrition, 5(6b), 1179-1196.

Alinia, S., Hels, O., \& Tetens, I. (2009). The potential association between fruit intake and body weight - A review. Obesity Reviews, 10, 639-647.

Bandura, A. (1977). Social Learning Theory. New York: General Learning Press.

Baranowski, T. (1997). Low Validity of a Seven-Item Fruit and Vegetable Food Frequency Questionnaire Among Third-Grade Students. Journal of the American Dietetic Association, 97(1), 66-68.

Barber, B. K., \& Harmon, E. L. (2002). Violating the self: parental psychologica control of children and adolescents. In: B.K. Barber (Ed.), Intrusive parenting. How psychological control affects children and adolescents, 15-52.

Barber, B. K. (1996). Parental psychological control: Revisiting a neglected construct. Child Development, 67, 3296-3319.

Baumrind, D. (1971). Current patterns of parental authority. Developmental Psychology, 4(1), 1-103.
Baumrind, D. (1966). Effects of authoritative parental control on child behavior. Child Development, 37, 887-907.

Beyers, W., \& Goossens, L. (1999). Emotional autonomy, psychosocial adjustment and parenting: Interactions, moderating and mediating effects. Journal of Adolescence, 22, 753-769.

Blanchette, L., \& Brug, J. (2005). Determinants of fruit and vegetable consumption among 6 to 12-year-old children and effective interventions to increase consumption. Journal of Human Nutrition and Dietetics, 18, 431-443.

Bogers, R. P., Van Assema, P., Kester, A. D. M., Westerterp, K. R., \& Dagnelie, P. C. (2004). Reproducibility, validity, and responsiveness to change of a short questionnaire for measuring fruit and vegetable intake. American Journal of Epidemiology, 159, 900-909.

Bronfenbrenner, U. (1979). The ecology of human development: experiments by nature and design. Cambridge, MA: Harvard University Press.

Brown, R., \& Ogden, J. (2004). Children's eating attitudes and behaviour: A study of the modelling and control theories of parental influence. Health Education Research, 19(3), 261-271.

Cooke, L. J., Wardle, J., Gibson, E. L., Sapochnik, M., Sheiham, A., \& Lawson, M. (2004). Demographic, familial and trait predictors of fruit and vegetable consumption by pre-school children. Public Health Nutrition, 7, 295-302.

Currie, C., Roberts, C., Morgan, A., Smith, R., Settertobulte, W., Samdal, O., \& Rasmussen, V. B. (2004). Young people's health in context. Health Behaviour in School-aged Children (HBSC) study: International report from the 2001/2002 survey. Health Policy for Children and Adolescents, No. 4. Copenhagen: WHO Regional Office for Europe.

Den Exter Blokland, E. A. W., Engels, R. \& Finkenauer, C. (2001). Parenting styles, self-control and male juvenile delinquency: The mediation role of self-control In M. Martinez (Ed.), Prevention And Control Of Aggression And The Impacts On Its Victims (pp. 201-207). Secaurus, NJ: Springer.

Darling, N., \& Steinberg, L. (1993). Parenting style as context: An integrative model. Psychological Bulletin, 113, 487-496.

Eurostat. (2007). Task Force on Core Social Variables. Final Report. Luxembourg: European Communitees.

Finkenauer, C., Engels, R. C. M. E., \& Baumeister, R. F. (2005). Parenting behaviour and adolescent behavioural and emotional problems: The role of self-control. International Journal of Behavioral Development, 29, 58-69.

Flay, B. R., Snyder, F. J., \& Petraitis, J. (2009). The theory of triadic influence. In R. J. DiClemente (Ed.), Emerging Theories in Health Promotion Practice and Research (2nd ed. New York: Jossey-Bass, pp. 451-510.

Gerards, S. M. P. L., Sleddens, E. F. C., Dagnelie, P. C., De Vries, N. K., \& Kremers, S. P. J. (2011). Interventions addressing general parenting to prevent or treat childhood obesity. International Journal of Pediatric Obesity, 6(2-2), e28-e45. doi:10.3109/17477166.2011.575147.

Gibson, E., Wardle, J., \& Watts, C. (1998). Fruit and vegetable consumption, nutritional knowledge and beliefs in mothers and children. Appetite, 31, 205-228.

Glass, D. C., \& Gray, C. N. (2001). Estimating mean exposures from censored data: Exposure to benzene in the Australian petroleum industry. Annals of occupational hygiene, 45, 275-282.

Goossens, L., \& Beyers, W. (1999). Parenting style and adolescent adjustment: A twoyear longitudinalstudy. Presented at the 9th European Conference on Developmental Psychology. Greece: Island of Spetses.

Gray, M. R., \& Steinberg, L. (1999). Unpacking authoritative parenting: Reassessing a multidimensional construct. Journal of Marriage and Family, 61, 574-587.

Guenther, P., Dodd, K., Reedy, J., \& Krebssmith, S. (2006). Most Americans eat much less than recommended amounts of fruits and vegetables. Journal of the American Dietetic Association, 106, 1371-1379.

Haraldsdottir, J., Thorsdottir, I., de Almeida, M. D. V., Maes, L., Perez Rodrigo, C. P., Elmadfa, I., \& Frost Andersen, L. (2005). Validity and reproducibility of a precoded questionnaire to assess fruit and vegetable intake in European 11- to 12-year-old schoolchildren. Annals of Nutrition and Metabolism, 49(4), 221-227.

Huver, R. M. E., Engels, R. C. M. E., Vermulst, A. A., \& De Vries, H. (2007a). Is parenting style a context for smoking-specific parenting practices? Drug and Alcohol Dependence, 89(2-3), 116-125.

Huver, R. M. E., Engels, R. C. M. E., Van Breukelen, G., \& De Vries, H. (2007b) Parenting style and adolescent smoking cognitions and behaviour. Psychology and Health, 22, 575-593.

Huybrechts, L., Matthys, C., Vereecken, C., Matthys, L., Temme, E., \& Van Oyen, H. (2008). Food intakes by pre-school children in Flanders compared with recommendations. International Journal of Environmental Research and Public Health, 5, 243-257.

Jones, L. R., Steer, C. D., Rogers, I. S., \& Emmett, P. M. (2010). Influences on child fruit and vegetable intake: sociodemographic, parental and child factors in a longitudinal cohort study. Public health nutrition, 13, 1122-1130.

Joyce, J. L., \& Zimmer-Gembeck, M. J. (2009). Parent feeding restriction and child weight. The mediating role of child disinhibited eating and the moderating role of the parenting context. Appetite, 52, 726-734.

Kelder, S. H., Perry, C. L., Klepp, K. I., \& Lytle, L. L. (1994). Longitudinal tracking of adolescent smoking, physical activity, and food choice behaviors. American Journal of Public Health, 84, 1121

Kerr, Margaret., \& Stattin, Håkan. (2000). What parents know, how they know it, and several forms of adolescent adjustment: Further support for a reinterpretation of monitoring. Developmental Psychology, 36, 366-380.

Kratt, P., Reynolds, K., \& Shewchuk, R. (2000). The role of availability as a moderator of family fruit and vegetable consumption. Health Education \& Behavior, 27, 471-482. 
Kremers, S. P. J., Brug, J., De Vries, H., \& Engels, R. C. M. E. (2003). Parenting style and adolescent fruit consumption. Appetite, 41, 43-50.

Kremers, S. P. J., De Bruijn, G. J., Visscher, T. L. S., Van Mechelen, W., De Vries, N. K., \& Brug, J. (2006). Environmental influences on energy balance-related behaviors: A dual-process view. International Journal of Behavioral Nutrition and Physical Activity, 3(1), 9.

Kremers, S. P. J. (2010). Theory and practice in the study of influences on energy balance-related behaviors. Patient Education and Counseling, 79, 291-298.

Lamborn, S. D., Mounts, N. S., Steinberg, L., \& Dornbusch, S. M. (1991). Patterns of competence and adjustment among adolescents from authoritative, authoritarian, indulgent, and neglectful families. Child development, 62, 1049-1065.

Lock, K., Pomerleau, J., Causer, L., Altmann, D. R., \& McKee, M. (2005). The global burden of disease attributable to low consumption of fruit and vegetables: Implications for the global strategy on diet. Bulletin of the World Health Organiszation, 83, 100-108.

Maccoby, E. E., \& Martin, J. A. (1983). Socialization in the context of the family: Parent-child interaction. In E. Hetherington (Ed.), Handbook of Child Psychology: Socialization, Personality and Social Development (pp. 1-101). New York, NY: Willey.

MacKinnon, D. P. (2008). Introduction to Statistical Mediation Analysis. New York, NY: Lawrence Erlbaum Associates.

Mikkilä, V., Räsänen, L., Raitakari, O. T., Pietinen, P., \& Viikari, J. (2004). Longitudinal changes in diet from childhood into adulthood with respect to risk of cardiovascular diseases: The cardiovascular risk in young finns study. European Journal of Clinical Nutrition, 58, 1038-1045.

O'Connor, T. G. (2002). Annotation: The 'effects' of parenting reconsidered: findings, challenges, and applications. Journal of Child Psychology and Psychiatry, 43, 555-572.

Ogden, J., Reynolds, R., \& Smith, A. (2006). Expanding the concept of parental control: A role for overt and covert control in children's snacking behaviour? Appetite, 47, 100-106.

Pearson, N., Atkin, A. J., Biddle, S. J. H., Gorely, T., \& Edwardson, C. (2010). Parenting styles, family structure and adolescent dietary behaviour. Public Health Nutrition, 13, 1245-1253.

Pearson, N., Biddle, S. J. H., \& Gorely, T. (2008). Family correlates of fruit and vegetable consumption in children and adolescents: A systematic review. Public Health Nutrition, 12, 267-283.

Pomerleau, J., Lock, K., Knai, C., \& McKee, M. (2005). Interventions designed to increase adult fruit and vegetable intake can be effective: A systematic review of the literature. The Journal of Nutrition, 135, 2486-2495.

Rasmussen, M., Krølner, R., Klepp, K. I., Lytle, L., Brug, J., Bere, E., \& Due, P. (2006). Determinants of fruit and vegetable consumption among children and adolescents: A review of the literature. Part I: Quantitative studies. International Journal of Behavioral Nutrition and Physical Activity, 3, 22.

Rhee, K. (2008). Childhood overweight and the relationship between parent behaviors, parenting style, and family functioning. The ANNALS of the American Academy of Political and Social Science, 615(1), 11.

Richtlijnen Voedselkeuze (Nutrition Guidelines), (2009). Retrieved from http://www.voedingscentrum.nl/nl/voedingscentrum/nieuws/richtlijnenvoedselkeuze.aspx.

Rodenburg, G., Kremers, S. P. J., Oenema, A., \& Van de Mheen, H. (2011). Psychological control by parents is associated with a higher child weight. International Journal of Pediatric Obesity, 6, 442-449.
Rosnow, R. L., \& Rosenthal, R. (1989). Statistical procedures and the justification of knowledge in psychological science. American Psychologist, 44, 1276-1284.

Schachter, S., Goldman, R., \& Gordon, A. (1968). Effects of fear, food deprivation, and obesity on eating. Journal of Personality and Social Psychology, 10(2), 91-97.

Singh, A. S., Chinapaw, M. J., Brug, J., Kremers, S. P., Visscher, T. L., \& Van Mechelen, W. (2009). Ethnic differences in BMI among Dutch adolescents: what is the role of screen-viewing, active commuting to school, and consumption of soft drinks and high-caloric snacks? The International Journal of Behavioral Nutrition and Physical Activity, 6, 23.

Sleddens, E., Gerards, S., Thijs, C., De Vries, N., \& Kremers, S. P. J. (2011). Genera parenting, childhood overweight and obesity-inducing behaviors: A review. International Journal of Pediatric Obesity, 6(2-2), e12-e27. doi:10.3109/ 17477166.2011.566339.

Snoek, H. M., Engels, R. C. M. E., Janssens, J. M. A. M., \& van Strien, T. (2007). Parenta behaviour and adolescents' emotional eating. Appetite, 49, 223-230.

Statistics Netherlands. (2000). Standaarddefinitie allochtonen. In Hoe doet het CBS dat nou? The Netherlands: Voorburg, pp. 24-25.

Stattin, H., \& Kerr, M. (2000). Parental monitoring: A reinterpretation. Child Development, 1072, 1085

Steinberg, L., Elmen, J. D., \& Mounts, N. S. (1989). Authoritative parenting, psychosocial maturity, and academic success among adolescents. Child Development, 1424, 1436

Steinberg, L., Lamborn, S. D., Darling, N., Mounts, N. S., \& Dornbusch, S. M. (1994) Over-time changes in adjustment and competence among adolescents from authoritative, authoritarian, indulgent, and neglectful families. Child Development, 65, 754-770.

Tabachnick, B. G., \& Fidell, L. S. (1996). Using multivariate statistics (3rd ed.). New York: HarperCollins.

Tinsley, B. J. (2003). How children learn to be healthy. Cambridge University Press.

Van Assema, P. Brug. J. Ronda, G. Steenhuis, I. \& Oenema, A. (2002). A short Dutch questionnaire to measure fruit and vegetable intake: Relative validity among adults and adolescents. Nutrition and Health, 16, 85-106.

Van Der Horst, K., Oenema, A., Ferreira, I., Wendel-Vos, W., Giskes, K., Van Lenthe, F. \& Brug, J. (2007a). A systematic review of environmental correlates of obesityrelated dietary behaviors in youth. Health Education Research, 22(2), 203-226.

Van Der Horst, K., Kremers, S., Ferreira, I., Singh, A., Oenema, A., \& Brug, J. (2007b) Perceived parenting style and practices and the consumption of sugarsweetened beverages by adolescents. Health Education Research, 22(2), 295-305.

Ventura, A. K., \& Birch, L. L. (2008). Does parenting affect children's eating and weight status? International Journal of Behavioral Nutrition and Physical Activity, 5, 15

Vereecken, C., Rovner, A., \& Maes, L. (2010). Associations of parenting styles parental feeding practices and child characteristics with young children's fruit and vegetable consumption. Appetite, 55, 589-596.

Wachs, T. D. (1999). Celebrating complexity: Conceptualization and assessment of the environment. In S. L. Friedman \& T. D. Wachs (Eds.), Measuring environment across the life span: Emerging methods and concepts (pp. 357-392). Washington, DC, US: American Psychological Association.

World Health Organization. (2002). The World Health Report. Reducing Risks, Promoting Healthy Life. Geneva: WHO.

World Health Organization. (2003). Diet, Nutrition and the Prevention of Chronic Diseases. Report of a Joint WHO/FAO Expert Consultation. Geneva: WHO.

Zeinstra, G. G., Koelen, M. A., Kok, F. J., Van der Laan, N., \& De Graaf, C. (2010) Parental child-feeding strategies in relation to Dutch children's fruit and vegetable intake. Public Health Nutrition, 13, 787-796. 